\title{
O desafio da dimensão social e política da fé
}

Gerson Lourenço Pereira

\section{Introdução}

A reflexão a respeito da dimensão social e política da fé é um convite a enveredarmos pelo caminho de um tipo de espiritualidade próprio ao cristianismo. Trata-se de uma espiritualidade encarnada, situada e interpelada no/pelo contexto sócio, econômico e político que, muitas vezes, transcende o institucional (eclesiástico), insere-se nos desafios/problemas suscitados por tal contexto e assume compromissos na sociedade.

Em sentido amplo, antropologicamente falando, fé é uma necessidade humana que nos impulsiona a ir em frente, esperançosamente diante da realidade da vida, seguindo a esteira colocada em verso por Gilberto Gil: "andar com fé eu vou, a fé não costuma falhar". Porém, nessa esteira proposta o que motiva a fé não é necessariamente decifrável. É, antes, uma arte comumente praticada por quem vivencia situações de desumanidade. Como disse Hebert Viana, é a "arte de viver da fé, só não se sabe fé em que".

Jung Mo Sung observa que ter fé em perspectiva cristã não significa tão somente afirmar a existência de Deus, tampouco o envio de Jesus Cristo como proposta de enlevação do olhar para o céu. Fé, fundamentalmente, é a capacitação oferecida para "perceber a presença libertadora de Deus no interior da história, no meio dos conflitos e lutas sociais e pessoais"1. Fé que se desenvolverá na solidariedade, na entrega e nas ações fruto da identificação com os/as que sofrem.

Cabe então uma pergunta: Qual é a realidade social e política que interpela hoje a fé cristã no mundo e, em particular, na América Latina? A partir dessa pergunta segue outra: quais são os desafios teológicos nesse contexto? Caminharemos na direção proposta por essas indagações.

\section{Conjuntura Sócio-Econômica e Política Atual: Alguns Aspectos}

Ignacio Ellacuría sonhou uma reversão histórica, estabelecendo o que denominou de "civilização da pobreza" contraposta à "civilização da riqueza". Como principal característica desta última apontou a oferta do desenvolvimento e da felicidade ${ }^{2}$. No contexto atual, tal oferta gera a utopia do bem estar que é ansiada pelos/as que vivem nas periferias da economia mundial. Sob a promessa da satisfação das necessidades básicas de todos, a "civilização da riqueza" se sustenta por princípios desumanizantes calcados no individualismo, no êxito e no bem-viver egoísta.

\footnotetext{
1 SUNG, Jung Mo. Sementes de Esperança: a fé em um mundo em crise. Petrópolis: Vozes, 2005,pp.10-11. 
As intuições gerais contidas na denúncia de Ellacuría dos males dessa "civilização" auxiliam-nos na descrição de alguns aspectos do atual quadro sócio-econômico e políticos. Abordaremos três: o neoliberalismo e a globalização, a cultura de consumo e a exclusão social.

\section{a) Neoliberalismo e Globalização}

Diante da complexidade do conceito, numa definição simplista, neoliberalismo é a prática político-econômica que se baseia nas idéias de alguns economistas monetaristas como Milton Friedman, dos EUA, e Friedrich August Von Hayek, da Inglaterra. A defesa fundamental que postulavam consistia na redução da ação do Estado na economia, considerando o fardo para os governos os investimentos no mercado. Dessa maneira, o Estado se torna responsável pela preservação da ordem política e econômica, abrindo às empresas privadas a possibilidade de investimento ${ }^{3}$.

A consagração e adoção do receituário neoliberal como solução para a crise econômica possibilitou a expansão do mercado em escala mundial. Atualmente, o mundo se encontra em processo de globalização. No que pense em termos positivos, uma vez considerando as possibilidades da formação de uma consciência e redes relacionais globais, a globalização econômica se desenrola pelo impulso do neoliberalismo, muito embora sua influência já apresente sinais de expiração em alguns países do Primeiro Mundo. Para a América Latina, as medidas neoliberais permitiram a participação no mercado mundial. Mais adiante analisaremos os efeitos dessa participação, bem como a crise que o modelo neoliberal atravessa.

A globalização estabelece uma nova ordem econômica marcada pela integração dos mercados. Somado ao Mercado Comum Europeu e ao NAFTA, o Mercosul compõe a agenda neoliberal garantindo a presença na concorrência sul americana pelo destaque dos países como melhores e maiores economias mundiais. Consequentemente, a nova ordem configura uma cultura (que poderia ser tipificada de pós-moderna) consumista fomentadora do mercado em boa parte do mundo ${ }^{4}$.

\section{b) A Cultura de Consumo}

O sistema capitalista gerou e se sustenta pela sociedade de consumo. Por seu turno, o neoliberalismo mantém uma cultura de consumo ${ }^{5}$. Sem adentrarmos pelo campo da

\footnotetext{
${ }^{3}$ A respeito da conceituação, origem e conseqüências do neoliberalismo: Cf. MORAES, Reginaldo. Neoliberalismo: de onde vem, para onde vai? São Paulo: Senac, 2001; HINKELAMMERT, Franz. Cultura de la esperanza y sociedad sin exclusion. San José: DEI, 1995, pp .68-114. No tocante ao processo que desencadeou até a consagração do neoliberalismo e sua relação/tensão com a conceituação de libertação no contexto latinoamericano: SUNG, Jung Mo. Teologia e Economia: repensando a teologia da libertação e utopias. Petrópolis: Vozes, 1994, pp.15-64. Também: COMBLIN, José. Cristãos Rumo ao Século XXI: nova caminhada de libertação. São Paulo: Paulus, 1996, pp.200-202.

${ }^{4}$ Para maior aprofundamento sobre o tema da globalização: IANNI, O. Teorias da Globalização. Civilização Brasileira: Rio de Janeiro, 1994. Ver também crítica teológica da globalização econômica, além de consideração como desafio para a Teologia da Libertação in: BOFF, Leonardo. $\boldsymbol{A}$ voz do arco-íris. Rio de Janeiro: Sextante, 2004, p. 2450. Trata-se de um capítulo dedicado a pontuar e estabelecer como motivação à reflexão o tema em questão.

${ }^{5}$ SUNG, Jung Mo. Sementes de Esperança, pp. 32-34.
} 
fundamentação e conceituação antropológica do vocábulo, entendemos como cultura de consumo a mentalidade subjacente que determina as expectativas, influencia relações e acaba por configurar a identidade da pessoa inserida no sistema. Quais seriam as expectativas, influências e identidade procedentes e manifestadas dessa e nessa cultura?

Ao redor da cultura de consumo estão a lógica e os princípios que regem o mundo das mercadorias, sejam elas materiais ou simbólicas. Elas são sinais que comunicarão quem será quem nas relações interpessoais. Dentro dessa lógica, o ter é praticamente sinônimo de ser. Assim, sou identificado ou diferenciado conforme o lugar em que estiver situado na escala social: se na classe alta, esbanjando bens de consumo; se na classe média, ansiando por alcançar tais bens; se na classe pobre, sonhando em melhorar a vida para adquirir mercadorias melhores.

Calcada no individualismo, a mentalidade consumista é o critério de discernimento para avaliar se uma vida é bem-sucedida, feliz ou decadente. Ela perpassará todos os meandros da sociedade, invadindo inclusive o campo religioso. É interessante notar que cada vez menos atende aos anseios espirituais dos indivíduos formas de espiritualidade comunitária, ascética ou de apelo à simplicidade e à modéstia. Cada vez mais proliferam religiosidades "menos exigentes", mais simples, menos racionais e mais sensoriais. Praticamente vem sendo constituída uma nova forma de religiosidade contemporânea, tipicamente neoliberal, reflexo dessa cultura de consumo. Essa religiosidade apresenta como mensagem de redenção a felicidade/prosperidade, em outros termos, a bênção do mercado ${ }^{6}$.

Uma característica dessa cultura é a ausência de padrões de consumo. Ela gera uma verdadeira compulsão por obtenção de bens. Na medida em que corro visando alcançar um bem, a linha de chegada avança e sou forçado a correr seguir consumindo mais. Sou seduzido pelos cinco sentidos e estimulado a despertar necessidades que antes não achava que possuía. E se perco a capacidade monetária para continuar correndo?

Na cultura de consumo, quem não consegue correr é consumidor falho. É o excluído do jogo, o marginal cuja presença e convívio são incômodos. Dessa maneira, a sociedade se torna um arquipélago em que cada indivíduo, situado em sua classe, forma sua própria ilha. Muitas vezes, em nome de sua autopreservação, protegido em sua fortaleza, arvorando para si o direito à liberdade de consumir o gozo do bem-estar, se torna prisioneiro em seu próprio universo.

Que lugar possui a pessoa alheia à cultura de consumo?

\footnotetext{
${ }^{6}$ Um fenômeno peculiar relacionado à mentalidade de consumo é a Teologia da Prosperidade. Originária dos movimentos de cura, prosperidade e crença do poder da fé dos anos 40, essa concepção doutrinária se consolidou nos anos 70 nos Estados Unidos, encontrando ambiente para a proliferação dos círculos carismáticos das igrejas históricas e pentecostais, conectando-se ao televangelismo que possibilitou sua difusão. O fundamento da Teologia da Prosperidade está na Confissão Positiva que afirma ter o cristão o poder de determinar a existência do que declara e decreta. Um bom ensaio crítico é encontrado em: PIEDRA, Arturo. Teologia da graça e teologia da prosperidade: a tentativa inacabada da concretização da fé cristã. In: BATISTA, Israel (Org.). Graça, cruz e esperança na América Latina. São Leopoldo: Sinodal; Quito: CLAI, 2005, pp. 121-154.
} 


\section{c) A Exclusão Social}

O neoliberalismo e a globalização, bem como a cultura de consumo geram a situação de destacamento, de exclusão social como resultado da lógica do mercado e reverberação do que, em proporções maiores, ocorre no cenário da nova ordem mundial estabelecida. Conforme mencionado acima, o modelo neoliberal demonstra sinais de expiração. José Comblin considerou, já como presságio da ruína do neoliberalismo na América Latina, a crise monetária no México em 1995, os tremores na economia vividos na Argentina e Brasil no mesmo período, bem como os movimentos de esquerda na Venezuela, Colômbia e Uruguai ${ }^{7}$.

Talvez o maior sinal da crise neoliberal seja o que antes fora denunciado: a exclusão social, econômica e política. Muito embora a lógica neoliberal se apresente como promessa de solução para a pobreza, no bojo de sua proposta segue a modernização da economia sob os custos sociais. Os que são mais cobrados são os países em desenvolvimento. Tais países enfrentam hoje o problema do aumento da pobreza, como o Panamá, onde 40\% da população vivem em tal condição ${ }^{8}$.

Quem seriam os excluídos? Dom Luciano Mendes de Almeida, às vésperas das eleições presidenciais brasileiras, em julho de 1994, comentava com preocupação tratarem-se daqueles/as sem significação social, o non sense, como diria Wittenstein. São o produto direto dos níveis crescentes de desemprego, do arrocho salarial como medida para controle da inflação e a falência de empresas endividadas e obsoletas ${ }^{9}$.

Como consequência, a situação de exclusão re-nomeia o conceito de pobreza. Nesse contexto, o desprovido posto à margem não é necessariamente o que integra a classe social dos pobres. Conforme a lógica do mercado, de acordo com a cultura de consumo, estes têm acesso aos bens mesmo que em menor quantidade e maior dificuldade. A pessoa excluída está abaixo do que é estabelecido como classe inferior. É aquele/a em estado de total desprovimento, de total anulação, sem acesso inclusive aos meios imprescindíveis de cidadania como educação, moradia, saúde e segurança.

Esses aspectos conjunturais interpelam a teologia e a fé cristã. Propõem algumas reflexões. Apontam desafios e iluminam uma práxis futura. E em que termos podemos refletir teologicamente sobre tal contexto?

\section{Desafios à Fé Cristã}

Diante da conjuntura sócio-econômica e política marcada pelo estabelecimento do neoliberalismo, pela cultura de consumo (com todas as implicações para o indivíduo na sociedade) e pela exclusão social, a fé cristã é desafiada e refletir e dar algumas respostas.

\footnotetext{
${ }^{7}$ COMBLIN, José. Cristãos Rumo ao Século XXI, pp. 202-203.

${ }^{8}$ Cf. SOCIAL WATCH: informe 2004. Miedos y misérias: obstáculos a la seguridad humana. Montivideo: Instituto del Tercer Mundo. 2004, p. 15.

9 ALMEIDA, Don Luciano Mendes; TAVARES, Maria da Conceição. Os excluídos: debate entre os autores. Petrópolis-Rio de Janeiro: Vozes - CERIS, 1995, p.14.
} 
Procuraremos, a seguir, corresponder a cada aspecto conjuntural até aqui mencionado com o olhar da teologia e da espiritualidade cristãs.

\section{a) A Idolatria do Mercado}

O modelo econômico neoliberal faz do mercado um verdadeiro ídolo ao concebê-lo como um ente que se autoregula ${ }^{10}$. Precisamente neste particular a teologia começa ser interpelada.

Há pelo menos vinte anos, discute-se a relação entre a teologia e economia. Essa relação é questionada tanto a partir do ponto de vista econômico como do teológico. Trata-se da evidência do amadurecimento da Teologia da Libertação, cuja maioridade permite ir além das mediações sócio-analíticas, avançando com a "teologização" dos supostos e pressupostos que a economia possibilita para a apreensão mais lúcida e consistente das estruturas que geram os males sociais ${ }^{11}$.

Vale lembrar que a Teologia da Libertação floresce e é fecundada no contexto capitalista como crítica desse sistema. Em 1982, Pablo Richard afirmou na obra coletiva "A luta dos deuses" que "o capitalismo não é ateu, mas sim idólatra" e, portanto, a afirmação da fé cristã passaria pela apostasia dos falsos deuses, sendo assim "antiidolátrica"12. Nessa perspectiva, Jung Mo Sung atenta que, ontologicamente, um ídolo pode ser um sistema sacralizado ou absolutizado. Os ídolos sempre são deuses da opressão que exigem devoção e sacrifícios. Se na sociedade tradicional eram produto das mãos humanas, na sociedade moderna são um produto humano não-intencional resultado da interação do indivíduo com essa suposta divindade invisível ${ }^{13}$.

Jung Mo Sung prossegue afirmando que "esta invisibilidade do ídolo e, portanto, da própria idolatria, permite à sociedade moderna se apresentar como secularizada, atéia". No entanto, ela é profundamente religiosa, devota do mercado fetichizado por quem exerce o poder no cenário político-econômico.

Quem é neoliberal dirá: "é preciso ter fé no mercado, não é preciso conhecer o mercado". Sua auto-regulação gerará o melhor resultado, minimizará a pobreza, eliminará as desigualdades. A questão é que toda sorte de custos sociais acima descritos são verdadeiras exigências sacrificiais feitas impiedosamente. Jung Mo Sung denuncia:

A idolatria provoca a inversão entre o bem e o mal, pois o mal realizado em nome de um deus deixa de ser mal e passa a ser um sacrifício necessário à

\footnotetext{
${ }_{11}^{10}$ COMBLIN, José. Cristãos Rumo ao Século XXI, p. 354.

11 Obra de referência a respeito desse diálogo: ASSMANN, Hugo; HINKELAMMERT, Franz. A Idolatria do Mercado: ensaio sobre economia e teologia. Petrópolis: Vozes. 1989. A respeito da maioridade da Teologia da Libertação: VV.AA. A maioridade da teologia da libertação. Revista Semestral de Estudos e Pesquisas em Religião. Ano IV, nำ 6, abril de 1986.

${ }_{12}$ RICHARD, Pablo. Nossa luta é contra os ídolos. In: VV.AA., A luta dos deuses. São Paulo: Paulinas, 1982, pp. 737. Apud: SUNG, Jung Mo. Teologia e Economia, p. 234.

${ }^{13}$ SUNG, Jung Mo. Teologia e Economia, pp. 235-236.
} 
salvação e, portanto, um bem. Por trás da desqualificação da discussão ética sobre a economia, está a idolatria do mercado, com a sua inversão entre o bem e o mal e a transformação de assassinatos em sacrifícios necessários para o bem geral ou para a salvação. Esse nível mais profundo da lógica da opressão do sistema de mercado... Trata-se de um objeto que não faz parte da metodologia das ciências modernas. Aqui, deve entrar a contribuição específica da crítica teológica ${ }^{14}$.

Nesses termos, a função da fé é ser força ideológica a favor da vida na luta antiidolátrica e antisacrificial. É anúncio e resistência à opressão perpetrada pela fetichização do mercado. Aqui indagamos: quem são as vítimas sacrificadas? Da mesma forma refletiremos a respeito em perspectiva teológica.

\section{b) Identificação das Vítimas Sacrificadas}

Como disse Comblin, por mais que o sistema neoliberal afirme que fará desaparecer a pobreza, "os pobres estão aí" como vítimas do mercado. Quem são? Em primeiro lugar, são aquelas pessoas "inempregáveis" sem condições para exercer uma função na sociedade ${ }^{15}$.

São os indigentes e indivíduos em subempregos que geram a população de rua, população esta que, desde os primeiros anos de existência desconhecem o significado da cidadania viabilizada pela educação e instituições civis. Em outros termos, são os pequeninos identificados como imagens de Jesus que, como ele, subiram ao calvário sem previsão de ressurreição no terceiro dia, daqui a três meses ou daqui a três anos.

O calvário representa a vitória, mesmo que temporária, do império e seu deus sobre a proposta de dignificação humana do Reino de Deus. Na sociedade moderna devota da idolatria do mercado, o calvário se apresenta renomeado como violência urbana, epidemia da dengue, analfabetismo, miséria, fome.

Tal identificação torna reconhecível a imagem de Cristo no mundo globalizado e neoliberal. Frente à vitória do ídolo e respondendo a uma provável indagação a respeito da presença e eficácia da ação do Deus da vida, Jürgen Moltmann dirá:

Jesus trouxe Deus para aqueles que, como ele, foram humilhados. A cruz está posta entre as inumeráveis cruzes que se somaram ao longo da história da humanidade, no caminho sangrento dos poderosos e violentos... Para tornar-se irmão dos humanos abandonados e achá-los em seu estado de privação, Jesus foi bem ao fundo do abandono divino, no estado em que se encontravam abandonados todos os seres humanos ${ }^{16}$.

\footnotetext{
${ }^{14}$ SUNG, Jung Mo. Teologia, espiritualidade e mercado. In: SUSIN, Luiz Carlos (org.). Teologia para outro mundo possível. São Paulo: Paulinas, 2006, p. 346.

${ }^{15}$ COMBLIN, José. Quais os desafios dos temas teológicos atuais? São Paulo: Paulus, 2005, p. 15.

${ }^{16}$ MOTMANN, Jürgen. Vida e Esperança. : um testamento para a América Latina. São Bernardo do Campo: EDITEO, 2008, p. 77.
} 
Humilhados nas suas cruzes, as vítimas têm a sua humanidade muitas vezes negada. Infelizmente, a exclusão da sociedade de consumo não permite sequer a consciência de sua dignidade como imagem do Cristo. Não experimentam a redenção, experimentando antes a condenação porque simplesmente não são por não terem. Como reclamou Gabriel O Pensador em uma de suas canções: "o que o mundo me pede, não é o que o mundo me dá".

Todavia, seria extremamente contraditório encerrarmos por aqui. Diria desesperançado e desesperador. Afinal, como citado acima, a fé cristã afirma a presença e ação de Deus na história e nos conflitos humanos. Por essa razão, correspondendo à mentalidade consumista que rege as relações interpessoais na sociedade contemporânea, assinalaremos o desafio da ressurreição da utopia como último desafio teológico.

\section{c) A Ressurreição da Utopia do Reino de Deus}

George Pixley propôs como tarefa teológica na sua reflexão a respeito do Reino de Deus que "contra a afirmação de um Deus criador auto-suficiente, afirmação esta de uma Igreja que se sente dona da sociedade e que se considera em paz com o mundo natural, devemos afirmar um Deus que é histórico e que luta ativamente para erguer os oprimidos e destruir os opressores"17. De que forma se processaria essa luta?

Reinado de Deus é ação soberana de um Deus de amor, justiça, solidariedade e paz. Nessa ação soberana Deus se revela, sobretudo naqueles/as destituídos e excluídos. "O excluído é o lugar de concentração da revelação de Deus. Junto com a revelação de Deus, nele se dá também a revelação da humanidade, da encarnação, da Igreja, da ação pastoral, da caridade cristã, da morte e ressurreição de Jesus" ${ }^{18}$. Esse excluído é o pobre por quem Cristo optou em sua agenda programática (cf. Lucas 4.16-19). Esse excluído é o pobre por quem deveríamos optar preferencialmente.

"Extra Pauperes Nulla Salus" (fora dos pobres não há salvação) ${ }^{19}$. Por isso é imperioso o envolvimento nas causas dos/as que não tem voz, da dignificação dos/as insignificantes na sociedade. Por isso é necessária a reversão dos rumos da história assumindo, como ponto de partida, o compromisso com a elaboração de uma visão alternativa do ser humano. A tarefa teológica seria cumprida contanto que a Igreja seja porta-voz do anúncio da graça, pois é na gratuidade que somos humanos. Consistiria em "mostrar à humanidade que o ser humano é humano antes da pertença a qualquer instituição ou antes de classificação por qualquer sistema social. Em outras palavras, o ser humano é um ser de dignidade antes de entrar no mercado e tornar-se consumidor e até mesmo estando excluído do mercado"20.

\footnotetext{
${ }^{17}$ PIXLEY, George. Reino de Deus. São Paulo: Paulinas, 1986, p. 120.

${ }^{18}$ FELLER, Vitor Galdino. A revelação de Deus a partir dos excluídos. São Paulo: Paulus, 1995, p. 119.

19 SOBRINO, Jon. Fora dos pobres não há salvação, p. 67.

${ }^{20}$ SUNG, Jung Mo. Teologia, Espiritualidade e mercado, p. 348.
} 
As sementes do Reino lançadas podem também gerar uma nova consciência que sirva de antídoto a algumas realidades refratárias como o consumismo, a desumanidade na concorrência regida pela lógica do mercado, a violência urbana. Sobre esta última, na procura de pistas de ação pastoral para superá-la, diz Jung Mo Sung:

Eu penso que uma linha de trabalho fundamental é a de recuperação da autoestima das pessoas desvinculadas da capacidade de consumo. Ajudar as pessoas a terem experiências que Ihes permitam perceber que são pessoas dignas não importando o que consomem. Uma verdadeira experiência espiritual... É, no fundo, a idéia de que a justificação da vida não se dá pelo consumo ou pelos títulos sociais ou religiosos, mas sim pela fé, esta capacidade de apostar e ver que todos os seres humanos têm a mesma dignidade fundamental e, por isso, devem ser tratados de acordo. ${ }^{21}$

No paradoxo "já e ainda não do Reino", é desafiador ao cristianismo lutar por um mundo mais justo e igualitário. É utópico acreditar que um dia isso acontecerá (ainda não). Contudo, integra a fé cristã crer e agir a partir do que ainda não aconteceu (já). O desafio atual seria "pensar a tensão entre a solidariedade social e a auto-organização do mercado, sem cair na idolatria do mercado ou na sua demonização" ${ }^{22}$. O caminho alternativo e possível de ser trilhado é o da humanização.

\section{Conclusão}

Encerro esta reflexão citando Vitor Feller, reafirmando assim o compromisso éticocristão junto aos excluídos de nossa sociedade:

Se Deus, para revelar-se, escolhe o caminho escandaloso da opção pelos pobres e excluídos, também cada cristão, para se revelar, isto é, para encontrar a verdade nuclear a seu respeito, e assim se realizar como homem novo em Cristo, deverá ser solidário com os excluídos ${ }^{23}$.

\section{Para refletir:}

1. Que alternativas humanizadoras encontraríamos ao consumismo?

2. Seria um sonho muito distante a construção da sociedade sobre as bases de uma economia solidária? Como ajudaríamos a erguê-la?

3. Como diminuir as mazelas sociais provocadas pelo consumismo e exclusão no atual sistema político e econômico? Poderíamos pensar em pequenas ações viáveis e significativas?

\footnotetext{
${ }^{21}$ SUNG, Jung Mo. Sementes de Esperança, pp. 96-97.

${ }^{22}$ SUNG, Jung Mo. Teologia, espiritualidade e mercado , p. 350.

${ }^{23}$ FELLER, Vitor Galdino. Revelação de Deus a partir dos excluídos, p. 120.
} 


\section{Bibliografia}

1. ALMEIDA, Don Luciano Mendes; TAVARES, Maria da Conceição. Os excluídos: debate entre os autores. Petrópolis-Rio de Janeiro: Vozes - CERIS, 1995.

2. ASSMANN, Hugo; HINKELAMMERT, Franz. A Idolatria do Mercado: ensaio sobre economia e teologia. Petrópolis: Vozes. 1989.

3. BATISTA, Israel (Org.). Graça, cruz e esperança na América Latina. São Leopoldo: Sinodal; Quito: CLAI, 2005.

4. BOFF, Leonardo. A voz do arco-íris. Rio de Janeiro: Sextante, 2004.

5. COMBLIN, José. Cristãos Rumo ao Século XXI: nova caminhada de libertação. São Paulo: Paulus, 1996.

6. Quais os desafios dos temas teológicos atuais? São Paulo: Paulus, 2005.

7. FELLER, Vitor Galdino. A revelação de Deus a partir dos excluídos. São Paulo: Paulus, 1995.

8. HINKELAMMERT, Franz. Cultura de la esperanza y sociedad sin exclusion. San José: DEI, 1995.

9. IANNI, O. Teorias da Globalização. Civilização Brasileira: Rio de Janeiro, 1994.

10. MORAES, Reginaldo. Neoliberalismo: de onde vem, para onde vai? São Paulo: Senac, 2001.

11. MOTMANN, Jürgen. Vida e Esperança. : um testamento para a América Latina. São Bernardo do Campo: EDITEO, 2008.

12. PIXLEY, George. Reino de Deus. São Paulo: Paulinas, 1986.

13. SOBRINO, Jon. Fora dos pobres não há salvação: pequenos ensaios utópicosproféticos. São Paulo:Paulinas, 2008.

14. SOCIAL WATCH: informe 2004. Miedos y misérias: obstáculos a la seguridad humana. Montivideo: Instituto del Tercer Mundo. 2004.

15. SUNG, Jung Mo. Teologia e Economia: repensando a teologia da libertação e utopias. Petrópolis: Vozes, 1994.

16. Sementes de Esperança: a fé em um mundo em crise. Petrópolis: Vozes, 2005.

17. SUSIN, Luiz Carlos (org.). Teologia para outro mundo possível. São Paulo: Paulinas, 2006.

18. VV.AA. A maioridade da teologia da libertação. Revista Semestral de Estudos e Pesquisas em Religião. Ano IV, № 6, abril de 1986. 